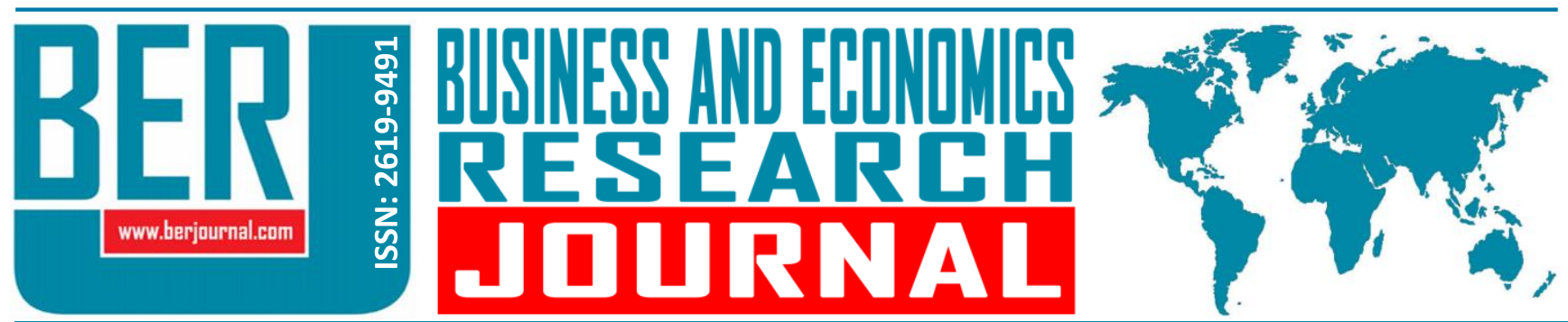

Business and Economics Research Journal Vol. 10, No. 1, 2019, pp. 27-40 doi: 10.20409/berj.2019.154

\title{
Türk Bankacılık Sektöründe Toplam Faktör Verimliliği İle Hissedar Getirisi İlişkisi*
}

\author{
Serhat Duranay ${ }^{\mathrm{a}}$, Gamze Gocmen Yagcilar ${ }^{\mathrm{b}}$
}

Öz: 2002-2016 yılları arasında Türk bankaları üzerine uygulanan bu çalışmanın başlıca üç amacı bulunmaktadır: (i) Türkiye'de faaliyet gösteren mevduat bankalarının Toplam Faktör Verimliliğini (TFV) incelemek, (ii) borsada ișlem gören ve görmeyen bankaların verimlilik değișimlerini karșılaștırmak ve (iii) borsada işlem gören bankaların verimlilik değişimi ile hissedar getirileri arasındaki ilişkiyi değerlendirmektir. Bu sayede, verimliliği artan bankaların hissedarlar getirilerinin de artacağı hipotezi sınanacaktır. Belirlenen amaçlar doğrultusunda, öncelikle ele alınan dönem için 22 bankanın verimlilik değişimi Malmquist TFV endeksi ile ölçülmüştür. Borsada işlem gören ve görmeyen bankaların verimlilik değişimleri arasında anlamlı bir fark bulunamamıștır. Ardından, 2007-2016 dönemi için borsada işlem gören 10 bankanın hissedar getirileri ve verimlilik değişimleri hesaplanmıştır. Yapılan ilk regresyon analizlerinde, TFV hissedar getirisi ile ilişkili bulunmazken, teknik etkinlik değişiminin, hissedar getirisi üzerinde pozitif ve anlamlı bir etkisinin olduğu görülmüştür. Ancak bu ilişkinin test edilmesi için kontrol değişkenleri (piyasa getirisi, defter değeri/piyasa değeri, aktif karlılığı) kullanılarak regresyon analizleri yinelenmiştir. Tekrarlanan regresyon analizlerinde elde edilen ilişkinin ortadan kalktığı sonucuna ulaşılmıştır.

\section{The Relationship between Total Factor Productivity and Shareholder Returns in Turkish Banking Sector}

Abstract: The study, which was conducted in Turkish Banks between 2002-206, has three main objectives: (i) to examine the Total Factor Productivity (TFP) of deposit banks operating in Turkey, (ii) to compare the productivity changes of banks that listed and non-listed listed on the stock exchange, and (iii) to evaluate the relationship between the change in productivity and shareholder returns of the listed banks. In this way, the hypothesis that "the shareholder returns of banks with increased productivity also increase" will be tested. In line with the stated objectives, the productivity change of 22 banks between examined period was measured by using the Malmquist TFP index. There was no significant difference between the productivity changes of the listed and non - listed banks. Then, for the period 2007-2016, the shareholder returns and productivity changes of 10 banks listed in the stock exchange were calculated. While there was no significant relationship between total factor productivity and shareholder returns, it was observed that the change in technical efficiency had a positive and significant effect on it. However, regression analyzes were repeated using control variables (market return, book value/market value, return on assets) to test this relationship. After repeated regression analysis, it was concluded that the relationship is disappeared.

Anahtar Sözcükler: Mevduat Bankaları, Malmquist TFV Hissedar Getirisi, Etkinlik, Verimlilik

JEL: G21, G30, D24

Gelis : 05 Ekim 2018

Düzeltme : 13 Kasım 2018

Kabul : : 14 Aralık 2018

Tür $\quad$ : Araștırma

Keywords: Deposit Banks, Malmquist TFP, Shareholder Return, Efficiency, Productivity

JEL: G21, G30, D24

Received : 05 October 2018

Revised : 13 November 2018

Accepted : 14 December 2018

Type : Research

a Res. Asst., Suleyman Demirel University, Faculty of Economics and Administrative Sciences, Department of Business Administration, Isparta, Turkiye, serhatduranay@sdu.edu.tr (ORCID ID: 0000-0002-3090-2764)

b Asst. Prof., PhD., Suleyman Demirel University, Faculty of Economics and Administrative Sciences, Department of Banking and Finance, Isparta, Turkiye, gamzeyagcilar@sdu.edu.tr (ORCID ID: 0000-0002-5009-4696) 


\section{Giriş}

Bankaların etkinlik, verimlilik ve performansları uzun yıllardır ilgi çeken çalışma alanlarından biri olmuştur. Bu çalışmalarda kullanılan farklı analiz teknikleri bulunsa da en çok ilgi gören analiz yöntemlerinden biri Veri Zarflama Analizi (VZA) ve VZA'ya zaman faktörü eklenerek verimlilik değerlerinin zamana göre değişimini incelemeye olanak tanıyan Malmquist Toplam Faktör Verimliliği (TFV) Endeksidir.

Yerli ve yabancı literatürde; farklı periyotlarda farklı girdi ve çıktı değişkenleri kullanılarak yapılmış çok sayıda Malmquist TFV endeksi çalışması bulunmaktadır. Ancak, bankacılık sektörü özelinde yapılmış ve verimlilik değişimi ile hissedar getirisi arasındaki ilişkiyi inceleyen çalışma sayısı oldukça kısıtıdır. Bu kısıtı çalışmaların sayısı, yerli literatüre inildikçe iyice azalmaktadır. Çalışmaların birçoğu, yalnızca verimlilik-etkinlik değişimlerini incelemeye ve çözüm önerileri geliştirmeye yönelik olsa da, bu değişimlerin farklı alanlar üzerindeki etkisinin de incelenmesi büyük faydalar sağlayacaktır. Özellikle, borsada işlem yapan yatırımcılar açısından, getirilerinin ne olacağı, bu getirilerin nelerden etkileneceği gibi sorulara cevap olması açısından verimlilik değişimlerinin hissedar getirisi üzerindeki etkisinin araştırılması önem arz etmektedir. Bu bağlamda ana hedef olarak BiST'de işlem gören mevduat bankalarının verimlilik değişimleri ile hissedar getirileri arasındaki ilişkiyi irdeleyen bu çalışma iki kısımdan oluşmaktadır.

İlk kısımda 2002-2016 yılları arasında aktif olarak Türk Bankacılık Sektöründe faaliyet gösteren bankalar arasından belirli kısıtlar altında seçilmiş 22 bankanın verimlilik değişimleri Malmquist TFV endeksi kullanılarak ölçülmüş, borsada işlem gören bankalar ile işlem görmeyen bankalar arasında anlamlı bir farklıık olup olmadığı test edilmiştir.

İkinci kısımda ise hissedar getirilerinin hesaplanabilmesi için, payları 2007-2016 yılları arasında Borsa İstanbul'da (BIST) sürekli işlem görmüş olan 10 banka ele alınmış, bu bankaların verimlilik değişimleri Malmquist TFV endeksi ile hesaplandıktan sonra verimlilik değişimleri ve hissedar getirileri arasında anlamlı bir iliş̧ki olup olmadığı irdelenmiştir.

\section{Literatür Taraması}

Malmquist TFV Endeksi temelde Veri Zarflama analizine dayanan bir metottur. VZA etkinlik çalışmaları için en çok kullanılan yöntem olup, bankacılık sektörü üzerinde bu yöntem kullanılarak yapılmış olan etkinlik çalışmaları girdi ve çıktı değişkenleri de gösterilerek Kurşun ve Kuşakçı' nın (2016) çalışmasında derlenmiştir.

Malmquist Toplam Verimlilik Endeksi kullanılarak yapılmış olan gerek ulusal gerekse uluslararası çalışmaların sayısı da oldukça fazladır. Ele alınan dönemler ve ülkeler farklılık gösterse de bu çalışmalarda elde edilen ortak sonuçlardan biri serbestleşme dönemlerinin ardından bankacilık sektörünün toplam faktör verimliliğinin artış gösterdiğidir. Berg, Forsund ve Jansen (1992), 1980-1989 yılları arasında Norveç, Canhoto ve Dermine (2003) 1990-1995 yılları arasında Portekiz ve Lee, Worthington ve Leong (2010) 1995-2005 yılları arasında Singapur bankalarının serbestleşme döneminde verimlilik değişimlerini incelemişler ve toplam faktör verimliliğinde bahsedilen artışın gerçekleştiğini ortaya koymuşlardır.

Devaney ve Weber (2000), 1990-1993 döneminde ABD tarım bankacılı̆̆ı sektöründe, Krishnasamy, Ridzwa ve Perumal (2004), 2000-2001 döneminde Malezya' da incelenen 10 ticari bankada, Mazgit ve Balaylar (2013), Türkiye'deki yerli ve yabancı sermayeli bankalarda gerçekleşen verimlilik artışının, Karacabey ve Arslan (2004) ise 1997-2000 döneminde Türkiye'de 43 bankada gerçekleşen verimlilik azalışının teknolojik değişimdeki artış ve azalışlardan kaynaklandığını ortaya koymuşlardır.

Sathye (2002) ise 1995-1999 yılları arasında Avustralya' da faaliyet gösteren 17 yerel bankanın toplam faktör verimliliğindeki gerilemenin genelde teknik etkinlikte yaşanan gerilemeden kaynaklandığını tespit etmiştir.

Etkinlik, verimlilik ve hisse senedi-hissedar getirisi arasındaki ilişkileri inceleyen çalışmalara uluslararası literatürde rastlanırken, Türkiye için yapılan çalışmaların daha çok TVF ve hisse senedi getirileri arasındaki ilişkiye yönelik olduğu görülmektedir. Bu çalışmalardan biri, Yalçıner Atan ve Boztosun' a (2005) aittir. Yalçıner, vd. (2005), 2000-2003 döneminde IMKB 100 endeksinde yer alan 52 şirketi kapsayan 
çalışmalarında Malmquist sonuçlarına göre, teknik etkinlik değişimi-teknolojik değişim ve teknik etkinlik değişimi-ölçek etkinliği değişimi ile hisse senedi getirileri arasında pozitif bir ilişki bulmuşlardır.

Benzer bir çalışma Kasman ve Kasman (2011) tarafından bankacılık sektörüne yönelik olarak yapılmıştır. Bu çalışmada 1998-2008 periyodunda, borsada işlem gören Türk ticari bankalarından teknik ve ölçek etkin ve verimli bankaların hisse senetlerinin, rakiplerine göre daha iyi performans gösterdiği tespit edilmiştir.

Chu ve Lim (1998) 1992-1999 döneminde Singapur'da, Majid ve Sufian (2008) 1997-2006 döneminde Çin'de, Aftab, Ahamad, Ullah ve Sheikh (2011) 2003-2007 döneminde Pakistan'da faaliyet gösteren bankalara yönelik olarak etkinlik ve hisse senedi getirileri arasındaki ilişkileri incelemişlerdir. Üç çalışmada da bankaların etkinliği ve hisse senedi performansı arasında pozitif ve anlamlı ilişkiler bulunmuştur. Liadaki ve Gaganis (2010) Avrupa Birliği bünyesindeki bankaların etkinliklerini stokastik sınır yaklaşımı ile ölçmüşler, etkinliğin hisse senedi fiyatlarını pozitif ve anlamlı bir şekilde etkilediğini ortaya koymuşlardır.

Bu çalışmanın amacıyla en iyi örtüşen üç çalışma, Guzman ve Reverte (2008), Fiordelisi ve Molyneux (2010) ile Wen, Wang ve Sun (2011)'e aittir. Guzman ve Reverte (2008), 2000-2004 dönemi için Malmquist TFV ile bankaların verimlilik değişimlerini ölçmüşler, etkinlik ve verimlilikleri artan bankaların hissedar değerlerinin de yükseldiğini tespit etmişlerdir. Fiordelisi ve Molyneux (2010), 1995-2002 döneminde 4 Avrupa ülkesinde faaliyet gösteren 171 banka için toplam faktör verimliliğinin hissedar getirilerindeki değişimleri iyi bir şekilde açıklayabildiğini göstermişlerdir. Ayrıca, teknolojik değişim, toplam faktör verimliliğinin hissedar değerinin değişimi üzerindeki en önemli bileşeni olduğu tespit edilmiştir. Wen, Wang ve Sun (2011) ise Çin'de faaliyet gösteren 16 bankayı kapsayan çalışmalarında teknik etkinlikteki değişimin teknolojik değişime göre, hissedar getirilerindeki değişimi açıklamada daha yeterli olduğunu bulmuşlardır.

\section{Malmquist Toplam Faktör Verimliliği Endeksi}

Çalışmada, ele alınan bankaların verimliliklerindeki değişimi inceleyebilmek için Malmquist Toplam Faktör Verimliliği Endeksi kullanılmıştır. Temelde Veri Zarflama analizine dayanan ve Caves, Christensen ve Diewert tarafından (1982) geliştirilen Malmquist TFV endeksi verimlilik değişimi ölçmede en sık kullanılan ve parametrik olmayan bir yöntemdir. Malmquist TFV endeksi, ortak bir teknoloji üzerinden, ele alınan her bir veri noktasının farklarının oranlarını hesaplar. Böylelikle iki veri noktası arasındaki toplam faktör verimliliğindeki değişmeyi ölçer (Cingi ve Tarım, 2000).

Ölçeğe göre sabit getiri varsayımı altında, çıktı odaklı Malmquist TFV endeksinin matematiksel gösterimi aşağıdaki şekildedir (Guzman ve Reverte, 2008: 2038):

$$
M_{0}\left(y_{s}, x_{s}, y_{t}, x_{t}\right)=\left[\frac{D_{0}^{s}\left(x_{t}, y_{t}\right)}{D_{0}^{s}\left(x_{x}, y_{s}\right)} \times \frac{D_{0}^{t}\left(x_{t}, y_{t}\right)}{D_{0}^{t}\left(x_{s}, y_{s}\right)}\right]^{1 / 2}
$$

Verilen formülde, $D_{0}^{s}\left(x_{t}, y_{t}\right)$ kalıbı, t döneminde elde edilen gözlemin, s dönemi teknolojisinden olan uzaklığını göstermektedir. $M_{0}$ değeri $1^{\prime}$ den büyükse, TFV $s$ döneminden $t$ dönemine büyüme göstermiş, $1^{\prime}$ den küçükse TFV azalma göstermiştir (Yalçıner vd., 2005: 179). Temelde verilen formül, s dönemdeki ve $t$ dönemdeki iki verimlilik endeksinin geometrik ortalamasıdır.

Malmquist TFV için verilmiş olan matematiksel gösterim aşağıdaki şekilde yazılabilir:

$$
\left(\left[\frac{D_{0}^{t}\left(x_{t}, y_{t}\right)}{D_{0}^{S}\left(x_{s}, y_{s}\right)}\right] \times\left[\frac{D_{0}^{s}\left(x_{t}, y_{t}\right)}{D_{0}^{t}\left(x_{t}, y_{t}\right)} \times \frac{D_{0}^{S}\left(x_{s}, y_{s}\right)}{D_{0}^{t}\left(x_{s}, y_{s}\right)}\right]^{1 / 2}\right)
$$


Verimlilik değişiminin ilk bileşeni Teknik Etkinlik Değişimi (TED) olarak adlandırılır ve bir karar verme biriminin üretim sınırına ne kadar yaklaştığını gösterir. Böylelikle, 1'den büyük değerler, bu sınıra bağlı olarak etkinlikteki artışı, 1'den düşük değerler ise etkinlikteki düşüşü ifade etmektedir (Guzman ve Reverte, 2008: 2039).

Ayrıca TED, Saf Etkinlikteki Değişim (SED) ve Ölçek Etkinlik Değişiminin (ÖED) çarpımından oluşmaktadır. TED'i oluşturan bileşenlerden SED ve ÖED 1'den büyük ise karar verme birimi yönetsel ve uygun ölçekte çalışmaktadır yorumu yapılabilmektedir (Yamaltdinova, Yıldız ve Eleren, 2016: 111)

Değişimin ikinci bileşeni ise teknolojide meydana gelen değişimin (Teknolojik Değişim-TD) büyüklüğünü ifade eder ve üretim sınııının iki dönem içerisinde ne kadar değiştiğini gösterir. Bu bileşende ise 1 'den büyük değerler teknolojik gelişimi, 1 'den küçük değerler ise teknolojik gerilemeyi ifade etmektedir (Guzman ve Reverte, 2008: 2039).

Teknolojik değişim, sadece üretim teknolojisinde meydana gelen yeniliklerden ibaret değildir. Bu bileşen aynı zamanda, ele alınan karar verme biriminin maruz kaldığı çevresel ve yönetsel faktörler ile girdi çıktı değişkenleri üzerinde alınmış olan her türlü kararın, izlenen politikanın da bir göstergesidir (Lorcu, 2010: 280)

Bu şekilde bir ayrıştırmanın yapılması toplam verimlilik değişiminin kaynakları hakkında bilgi vermesi açısından önemlidir.

\section{Türk Bankacılık Sektörünün Verimlilik Değişiminin Analizi}

\subsection{Veri Setinin Oluşturulması}

Çalışmanın ilk aşamasında 2002-2016 döneminde sürekli faaliyet gösteren mevduat bankaları üzerinden analizler yapılmıştır. Ancak analiz sonuçlarını olumsuz etkileyeceği düşüncesiyle, TMSF'ye devredilmiş bulunan Birleşik Fon Bankası A.Ş. ve Türkiye'de yalnızca şube açmış olan yabancı sermayeli mevduat bankaları analiz dışı bırakılmıştır. íkinci aşamada ise, verimlilik seviyesi ve hissedar getirisi arasındaki ilişkinin incelenmesi amaçlanmıştır. Bu kısımda bağımsız değişken olarak verimlilik değerleri, bağımlı değişken olarak ise hissedar değerini ölçecek, piyasa verileri baz alınarak hisse fiyatlarındaki artış ve dağıtılan temettü üzerinden hesaplanan toplam hissedar getirisi ele alınmıştır. Bu bağlamda, ikinci aşama analizlerine dahil edilecek mevduat bankalarının 2007-2016 yılları arasında Borsa İstanbul (BIST)'te işlem gören mevduat bankaları olarak seçilmesi uygun görülmüştür. Çalışmada ele alınan bankalar Tablo 1 ve Tablo 2'de gösterilmiştir.

Tablo 1. 2002-2016 Döneminde Sürekli Faaliyet Gösteren Mevduat Bankaları

\begin{tabular}{|l|l|}
\hline Akbank & ICBC \\
\hline Alternatifbank & ING Bank \\
\hline Anadolubank & Şekerbank \\
\hline Arap Türk Bankası & TEB \\
\hline Burgan Bank & T.C. Ziraat Bankası \\
\hline Citibank & Turkish Bank \\
\hline Denizbank & Turkland \\
\hline Fibabanka & Türkiye Halk Bankası \\
\hline QNB Finansbank & Türkiye İş Bankası \\
\hline Garanti Bankası & Vakıf Bank \\
\hline HSBC & Yapı Kredi Bankası \\
\hline
\end{tabular}


S. Duranay - G. Gocmen-Yagcilar

Tablo 2. 2007-2016 Yıl Sonu Verileri Itibariyle BiST’ te Yer Alan Bankalar

\begin{tabular}{|l|l|}
\hline Akbank & Şekerbank \\
\hline Denizbank & Türkiye Halk Bankası \\
\hline QNB Finansbank & Türkiye İş Bankası \\
\hline Garanti Bankası & Vakıf Bank \\
\hline ICBC & Yapı Kredi Bankası \\
\hline
\end{tabular}

Bankacılık sektörü üzerine yapılmış verimlilik çalışmalarında, hangi girdi-çıktı değişkenlerinin kullanılacağı, üzerinde tartışılan bir konu olmuş ve bu durumla ilgili üç temel yaklaşım geliştirilmiştir. Bu yaklaşımlar; bankaları üretim yapan sistemler olarak gören ve değişkenleri adet olarak ele alan üretim yaklaşımı, bankaları toplamış oldukları mevduatları kredi ve diğer varlıklara dönüştüren aracı kurumlar olarak gören ve parasal değerleri dikkate alan aracılık yaklaşımı ve bankaların kârlarını maksimum, maliyetlerini ise minimum seviyeye getirmek amaçlarına dayanarak verilen faizleri girdi, alınan faiz ve faiz dışı gelirleri ise çıktı kabul eden karlılık yaklaşımıdır (Cingi ve Tarım, 2000; Drake vd., 2005: 4)

Bu çalışma kullanılan girdi ve çıktı değişkenleri bağlamında aracılık ve karlılık yaklaşımlarını bir arada ele alan bir karma yaklaşıma dayandırıımışıı. Girdi ve çıktıların belirlenmesinde temel olarak Guzman ve Reverte (2008) referans alınmıştır.

Tablo 3. Girdi ve Çıktı Değişkenleri

\begin{tabular}{|l|l|}
\hline Girdi & Çıktı \\
\hline Mevduat & Krediler \\
Faiz Giderleri + Verilen Ücret ve Komisyonlar & Faiz Gelirleri + Alınan Ücret ve Komisyonlar \\
Personel Giderleri & Menkul Değerler Cüzdanı \\
\hline
\end{tabular}

Bankalara ilişkin girdi-çıktı değişkenleri Türkiye Bankalar Birliği'nin veri tabanından derlenmiştir. Çalışmada ölçeğe göre sabit getiri varsayımı altında, çıktı odaklı Malmquist TFV endeksi kullanılmıştır.

\subsection{Borsada İşlem Gören ve Görmeyen Bankaların TFV'nin Karşılaştırılması}

2002-2016 yılları arasında sürekli faaliyette bulunan 22 mevduat bankası üzerinden hesaplanan sektöre ait verimlilik değişimleri Tablo 4'te gösterilmiştir. Malmquist TFV endeksinin 1'den büyük olması verimlilik artışını, 1'den küçük olması verimlilik azalışını 1'e eşit olması ise verimlilikte herhangi bir değişiklik olmadığını gösterir.

Tablo 4. Yıllar İtibariyle Ortalama Verimlilik Değişimleri

\begin{tabular}{|c|c|c|c|c|c|}
\hline Yıl & $\begin{array}{c}\text { Teknik Etkinlik } \\
\text { Değişimi }\end{array}$ & Teknolojik Değişim & $\begin{array}{c}\text { Saf Teknik } \\
\text { Etkinlik Değişimi }\end{array}$ & $\begin{array}{c}\text { Ölçek Etkinliğindeki } \\
\text { Değişim }\end{array}$ & $\begin{array}{c}\text { Malmquist TFV } \\
\text { Değişimi }\end{array}$ \\
\hline 2016 & 1,067 & 0,854 & 1,055 & 1,012 & 0,911 \\
\hline 2015 & 1,007 & 1,003 & 1,017 & 0,990 & 1,010 \\
\hline 2014 & 0,994 & 1,059 & 0,998 & 0,995 & 1,052 \\
\hline 2013 & 0,991 & 0,973 & 0,990 & 1,001 & 0,964 \\
\hline 2012 & 1,051 & 0,973 & 1,030 & 1,021 & 1,023 \\
\hline 2011 & 0,821 & 1,318 & 0,904 & 0,908 & 1,082 \\
\hline 2010 & 0,911 & 1,046 & 0,993 & 0,918 & 0,953 \\
\hline 2009 & 1,122 & 0,862 & 1,054 & 1,065 & 0,967 \\
\hline 2008 & 1,153 & 0,844 & 1,014 & 1,137 & 0,973 \\
\hline 2007 & 1,009 & 0,964 & 1,000 & 1,009 & 0,973 \\
\hline 2006 & 0,932 & 1,137 & 0,964 & 0,967 & 1,060 \\
\hline 2005 & 0,915 & 1,046 & 0,969 & 0,944 & 0,957 \\
\hline 2004 & 0,975 & 0,942 & 0,989 & 0,987 & 0,919 \\
\hline 2003 & 1,047 & 0,925 & 0,994 & 1,053 & 0,968 \\
\hline Ortalama & 0,996 & 0,989 & 0,997 & 0,999 & 0,985 \\
\hline
\end{tabular}




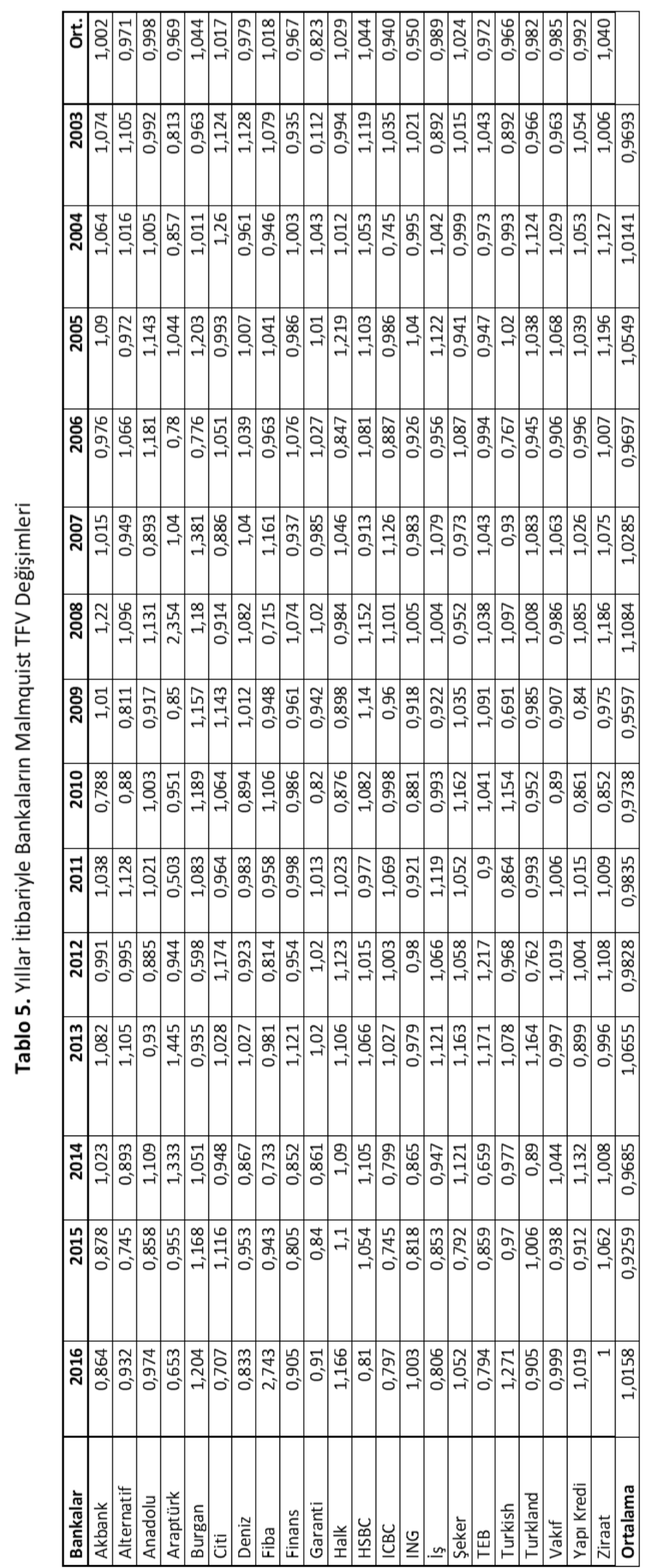


Elde edilen sonuçlara göre, 2003, 2004, 2005, 2007, 2008, 2009, 2010, 2013 ve 2016 yıllarında bankacılık sektöründe TFV azalış; 2006, 2011, 2012, 2014 ve 2015 yıllarında ise artış göstermiştir. Verimlilik artışının gerçekleştiği 2006, 2011 ve 2014 yıllarında bu artışın sebebi TD'de meydana gelen artıştır. Bu dönemlerde TED, TD’nin aksine negatif olarak gerçekleşmiş yani azalma göstermiştir. 2012 yılında gerçekleşen verimlilik artışı ise TED artıştan kaynaklanmış olup bu dönemde TD negatif yönlü gerçekleşmiştir. 2015 yılında ise hem TED hem de TD artış göstermiştir. Verimlilik artışının en fazla $(\% 8,2)$ olduğu yıl 2011 yılıdır. Bu dönemdeki artış TD'deki \%31,8'lik yüksek artış oranından kaynaklanmaktadır. Ayrıca 2007, 2008, 2009, 2012 ve 2016 yıllarında SED ve ÖED 1'den büyük çıkmıştır, bu yıllar için ele alınan bankalar genel anlamda yönetsel olarak etkin ve uygun ölçekte çalışmıştır.

Ele alınan tüm dönemlerin aritmetik ortalamasına bakıldığında, Akbank, Burgan, Citi, Fiba, Halk, HSBC, Şeker ve Ziraat Bankası Malmquist TFV değerleri artış göstermiştir. Tüm dönemlerdeki verimlilik değişimleri incelendiğinde en yüksek verimlilik artışını \%4,4 ile Burgan ve HSBC gerçekleştirmiştir. Aynı şekilde tüm dönemler boyunca ortalama verimliliği en fazla düşen banka ise \%17,7 ile Garanti olmuştur.

Payları borsada işlem gören ve görmeyen bankaların verimlilik değişimleri arasında anlamlı bir farklılık olup olmadığının tespiti için Mann-Whitney $U$ testi yapılmışıı. Mann-Whitney $U$ testi, belirli bir değişkene ilişkin olarak iki grup arasında anlamlı bir fark olup olmadığını ortaya koyar. Elde edilen sonuçlar Tablo 6’da yer almaktadır.

Tablo 6. Verimlilik Kümesi ve Borsada İşlem Görme Durumu: Mann-Whitney U Testi Sonuçları

\begin{tabular}{|l|l|c|c|c|}
\hline & \multicolumn{1}{|c|}{ Kümeler } & Sıra Ortalaması & $\mathbf{Z}$ & Anlamlılık \\
\hline \multirow{3}{*}{ TFVD } & 1: borsada işlem görenler & 152,23 & \multirow{2}{*}{$-0,456$} & \multirow{2}{*}{0,649} \\
\cline { 2 - 3 } & $\begin{array}{l}\text { 0: borsada işlem } \\
\text { görmeyenler }\end{array}$ & 152,23 & -23 \\
\hline
\end{tabular}

Mann-Whitney U Testi sonuçlarına göre anlamlılık değeri 0,649 çıkmış, payları borsada işlem gören bankalar ile görmeyen bankaların verimlilik değişimleri arasında anlamlı bir farklılık bulunamamıştır.

\section{Belirlenmesi}

4.3. Borsada İşlem Gören Mevduat Bankalarının TFV ve Hissedar Getirileri Arasındaki iliş̧kinin

Çalışmanın bu bölümünde 2007-2016 yılları arasında payları BiST'te işlem gören mevduat bankalarının verimlilik değişimleri kendi içlerinde kıyaslanarak incelenmiş ve verimlilik değişimi ile hissedar getirileri arasındaki ilişki araştırılmıştır.

Tablo 7'de 2007-2016 döneminde yıllar bazında ortalama verimlilik değişimleri gösterilmiştir.

Tablo 7. 2007-20016 Dönemi Borsada İşlem Gören Bankaların Ortalama Verimlilik Değişimleri

\begin{tabular}{|c|c|c|c|c|c|}
\hline YIL & $\begin{array}{c}\text { Teknik Etkinlik } \\
\text { Değişimi }\end{array}$ & Teknolojik Değişim & $\begin{array}{c}\text { Saf Teknik } \\
\text { Etkinlik Değişimi }\end{array}$ & $\begin{array}{c}\text { Ölçek Etkinliğindeki } \\
\text { Değişim }\end{array}$ & $\begin{array}{c}\text { Malmquist TFV } \\
\text { Değişimi }\end{array}$ \\
\hline 2016 & 1,055 & 0,760 & 1,027 & 1,027 & 0,801 \\
\hline 2015 & 1,001 & 0,971 & 0,998 & 1,002 & 0,972 \\
\hline 2014 & 1,007 & 1,018 & 1,003 & 1,003 & 1,025 \\
\hline 2013 & 0,995 & 0,922 & 1,004 & 0,991 & 0,918 \\
\hline 2012 & 1,013 & 1,000 & 1,004 & 1,010 & 1,013 \\
\hline 2011 & 0,980 & 1,057 & 0,996 & 0,984 & 1,036 \\
\hline 2010 & 0,994 & 0,952 & 1,002 & 0,992 & 0,947 \\
\hline 2009 & 1,019 & 0,838 & 1,002 & 1,017 & 0,854 \\
\hline 2008 & 0,962 & 1,046 & 0,974 & 0,988 & 1,006 \\
\hline 2007 & 1,040 & 0,983 & 1,021 & 1,018 & 1,022 \\
\hline Ortalama & 1,006 & 0,950 & 1,003 & 1,003 & 0,956 \\
\hline
\end{tabular}


Payları borsada işlem gören mevduat bankalarının verimlilik değişimleri yıllar bazında özet olarak incelendiğinde; 2007, 2008, 2011, 2012 ve 2014 yıllarında verimlilik artışı olduğu ve en büyük artışın 1,036 ile $(\% 3,6) 2011$ yılında gerçekleştiği görülmektedir. Ancak bu yılın hemen ardından verimlilik değerleri düşüş göstermiştir. 2012 yılında yaşanan krizin bu verimlilik düşüşü üzerinde etkisi olduğu söylenebilir. 2009, 2010, 2013, 2015 ve 2016 yılları ise bankaların verimlilik değişimlerinin negatif olarak gerçekleştiği yıllardır. Özellikle 2016 yılındaki \%19,9'luk verimlilik düşüşü dikkat çekmektedir. 2016 yılında teknolojik gerileme \%24 seviyelerinde gerçekleşmiş, bankalar etkin sınırı yakalamaya çalışmışlarsa da bu çaba verimlilik düşüşüne engel olamamıştır.

İncelenen 10 dönemde ise ortalama \%4,4'lük bir verimlilik düşüşü gözlemlenmiştir. Bu düşüşün sebebi TD'de yaşanan $\% 5^{\prime}$ lik azalmadır. TED'de yaşanan $\% 0,6^{\prime}$ lık yükseliş ise TFV endeksini yükseltmeye yeterli olmamıştır. 2009 ve 2016 yıllarındaki verimlilik değişimlerinin son 10 yıldaki ortalama verimlilik düşüşünün temel sebebi olduğu rahatlıkla söylenebilmektedir.

Tablo 8. 2007-2008 Dönemi Borsada İşlem Gören Bankalar Bazında Malmquist TFV Değişimleri

\begin{tabular}{|l|c|c|c|c|c|c|c|c|c|c|c|}
\hline Bankalar & $\mathbf{2 0 1 6}$ & $\mathbf{2 0 1 5}$ & $\mathbf{2 0 1 4}$ & $\mathbf{2 0 1 3}$ & $\mathbf{2 0 1 2}$ & $\mathbf{2 0 1 1}$ & $\mathbf{2 0 1 0}$ & $\mathbf{2 0 0 9}$ & $\mathbf{2 0 0 8}$ & $\mathbf{2 0 0 7}$ & Ort. \\
\hline Akbank & 1,033 & $\mathbf{1 , 0 5 2}$ & 1,040 & 0,921 & $\mathbf{1 , 0 3 4}$ & 1,085 & 0,977 & 0,687 & 1,122 & 0,943 & 0,981 \\
\hline Deniz & 1,050 & 1,006 & 1,063 & 0,916 & 1,043 & 1,127 & 1,005 & 0,833 & 1,016 & 0,976 & 1,000 \\
\hline Finans & 0,967 & 0,983 & 1,026 & 1,003 & 0,933 & 1,089 & 1,007 & 0,919 & 1,016 & 0,956 & 0,989 \\
\hline Garanti & 0,108 & 0,992 & 0,997 & 0,983 & 0,954 & 1,011 & 1,008 & 0,860 & 1,028 & 0,994 & 0,786 \\
\hline Halk & 0,961 & 0,975 & 1,049 & 0,968 & 0,990 & 0,936 & 0,921 & 0,903 & 1,004 & 1,197 & 0,988 \\
\hline ICBC & 1,039 & 0,772 & 1,009 & 0,820 & 1,139 & 1,152 & 0,805 & 1,023 & 0,951 & 0,976 & 0,960 \\
\hline İs & 0,994 & 0,993 & 1,028 & 0,848 & 1,018 & 0,996 & 0,919 & 0,725 & 1,040 & 1,139 & 0,963 \\
\hline Şeker & 1,000 & 0,989 & 1,047 & 0,941 & 1,004 & 0,975 & 1,053 & 0,890 & 0,996 & 1,023 & 0,990 \\
\hline Vakıf & 0,929 & 0,987 & 0,981 & 0,904 & 1,001 & 0,951 & 0,887 & 0,876 & 0,954 & 0,994 & 0,946 \\
\hline Yapı Kredi & 1,040 & 0,999 & 1,013 & 0,890 & 1,027 & 1,061 & 0,910 & 0,870 & 0,947 & 1,050 & 0,978 \\
\hline
\end{tabular}

Yıllar itibariyle bankalar tek tek incelendiğinde ise hiçbir bankanın verimlilik değerleri tüm yıllar boyunca artış göstermemiştir. Sadece Denizbank'ın tüm dönemlerin aritmetik ortalamasına göre verimlilik değeri sabit kalmış, geri kalan bankaların ise ortalama verimlilik değerleri düşmüştür, özellikle Garanti Bankası'nın verimlilik düşüşü dikkat çekmektedir.

\subsubsection{Hissedar Getirilerinin Hesaplanması}

Yüksek verimlilik artışı sergileyen bankaların yüksek hissedar getirisi sağlayacağı hipotezinin test edilebilmesi için, BiST'te işlem gören bankaların 2007-2016 dönemine ait 10 yıl için hissedar getirileri hesaplanmıştır.

Hissedar getirisi yıl içinde hisse fiyat değişimleri ve o yıl hisse başına dağıtılan temettüden oluşmaktadır. Bu bağlamda hissedar getirisi aşă̆ıdaki şekilde ifade edilebilir.

$$
H, G=\frac{P_{i t}-P_{i t-1}+d_{i t}}{P_{i t-1}}
$$

Formülde $P_{i t}$, i bankasının t yılı sonundaki hisse fiyatını, $P_{i t-1}$, i bankasının t yılı başındaki hisse fiyatını, $d_{i t}$ ise, i bankasının t yılında dağıttığı temettüleri göstermektedir. 
Tablo 9. Tanımlayıcı İstatistikler

\begin{tabular}{|l|c|c|c|c|}
\hline & His. Getirisi & TFV & TED & TD \\
\hline Ortalama & 0,1903 & 0,9724 & 1,0075 & 0,9665 \\
Medyan & 0,0659 & 0,9940 & 1,0000 & 0,9935 \\
Maksimum & 2,4754 & 1,1970 & 1,2680 & 1,1520 \\
Minimum & $-0,7740$ & 0,1080 & 0,8730 & 0,1080 \\
Standart Sapma & 0,6097 & 0,1207 & 0,0523 & 0,1208 \\
Gözlem Sayısı & 100 & 100 & 100 & 100 \\
\hline
\end{tabular}

Tablo 9, ele alınan 10 yıllık dönemde, 10 banka üzerinden toplam 100 gözleme ait hissedar getirisi, TFV, TED ve TD tanımlayıcı istatistikleri sunmaktadır. Elde edilen verilere göre, ortalama hissedar getirisinin 0,1903 olarak gerçekleştiği görülmektedir. Hissedarların getirisi en fazla $\% 147,54$ seviyesine çıkmış, en büyük kayıp ise \%22,6 olarak gerçekleşmiştir. TFV ve TD ortalama $\% 2,76$ ve \%3,35 azalmış, TED ise $\% 0,75$ artmıştır.

Hissedar getirilerine ait yıllık bazda tanımlayıcı istatistikler ise Tablo 10' da verilmiştir.

Tablo 10. Hissedar Getirilerine İlişkin Tanımlayıcı İstatistikler

\begin{tabular}{|l|c|c|c|c|c|c|c|c|c|c|}
\hline & $\mathbf{2 0 0 7}$ & $\mathbf{2 0 0 8}$ & $\mathbf{2 0 0 9}$ & $\mathbf{2 0 1 0}$ & $\mathbf{2 0 1 1}$ & $\mathbf{2 0 1 2}$ & $\mathbf{2 0 1 3}$ & $\mathbf{2 0 1 4}$ & $\mathbf{2 0 1 5}$ & $\mathbf{2 0 1 6}$ \\
\hline Ort. & 0,5037 & $-0,5475$ & 1,1649 & 0,1879 & $-0,2914$ & 0,5866 & $-0,1591$ & 0,2713 & $-0,0135$ & 0,1997 \\
\hline Std. Sap. & 0,6484 & 0,1839 & 0,6239 & 0,2164 & 0,1872 & 0,4079 & 0,1810 & 0,2384 & 0,3949 & 0,6007 \\
\hline Maks. & 1,9510 & $-0,1860$ & 2,4754 & 0,5423 & 0,1045 & 1,0230 & 0,1967 & 0,7671 & 0,9275 & 1,8563 \\
\hline Min. & $-0,1116$ & $-0,7740$ & 0,4773 & $-0,0875$ & $-0,4753$ & $-0,1042$ & $-0,3108$ & $-0,1133$ & $-0,3084$ & $-0,2976$ \\
\hline Gözlem Sayısı & 10 & 10 & 10 & 10 & 10 & 10 & 10 & 10 & 10 & 10 \\
\hline
\end{tabular}

Tablo 10'a bakıldığında, bankaların hissedar getirilerinin en yüksek olduğu yılın 2009 olduğu görülmektedir. İlgili yılda tüm bankaların hissedar getirileri pozitif olmuştur. Getirilerin en düşük olduğu yıl ise 2008 yılıdır. Bu yılda tüm bankalar hissedarlarına yıllık bazda negatif getiri sağlamıştır.

\subsubsection{TFV-Hissedar Getirisi illişkisi-Regresyon Analizi}

2007-2016 döneminde sürekli olarak borsada işlem gören 10 adet bankanın kendi aralarındaki nispi verimlilik değişimlerinin ve yıllık bazda hissedar getirilerinin hesaplanmasının ardından, bu iki değişken arasındaki ilişki ilk olarak regresyon analizi ile araştırılmıştır. Bu amaçla 3 ayrı panel regresyon modeli kurularak, Malmquist analizinden elde edilen sonuçların hissedar getirisini açıklama gücü test edilmiştir. Rassal etkiler yöntemiyle gerçekleştirilen analizlerden elde edilen bulgular Tablo 11' de yer almaktadır.

$$
H G_{i t}=\alpha_{0}+\beta_{1} V D_{i t}+u_{i t}
$$

4 numaralı formül, sözü edilen dört ayrı regresyon modelinin ortak ifadesidir. Bu modelde HG Hissedar getirisini, VD ise Toplam faktör verimlilik değişimi (TFV), teknik etkinlik değişimi (TED) ve teknolojik değişim (TD) olarak üç farklı değişkeni ifade etmektedir.

Tablo 11. Verimlilik Değişimi-Hissedar Getirisi: Panel Veri Analizi Sonuçları

\begin{tabular}{|l|c|c|c|c|c|}
\hline Bağımlı Değişken: Hissedar Getirisi & $\begin{array}{c}\text { Hausman } \\
\text { Testi } \\
\text { Prob. }\end{array}$ & $\begin{array}{c}\text { Regresyon } \\
\text { Katsayısı }\end{array}$ & $\begin{array}{c}\text { Olasılık } \\
\text { Değeri }\end{array}$ & $R 2$ & $D-W$ \\
\hline Bağımsız Değişkenler & 0,8809 & $-0,607888$ & 0,2527 & 0,014485 & 2,859818 \\
\hline Toplam Faktör Verimliği Değişimi & 0,6861 & 4,055635 & 0,0006 & 0,12081 & 2,689106 \\
\hline Teknik Etkinlik Değişimi & 0,9801 & $-1,326152$ & 0,0113 & 0,069059 & 2,774101 \\
\hline
\end{tabular}


Tablo 11 incelendiğinde, TFV değişkeninin anlamlılık değerlerinin 0,05'in üzerinde, TED ve TD değişkenlerinin anlamlılık değerlerinin ise $0,05^{\prime}$ in altında olduğu görülmektedir. Buna göre TVF, hissedar getirisini açıklamada istatistiksel olarak anlamlı bir sonuç vermemiştir. Ancak TED ve TD için ayrı ayrı bakıldığında istatistiksel olarak anlamlı etkiler bulunmuştur. TED ile hissedar getirisi arasında pozitif ve anlamlı, TD ile hissedar getirisi arasında ise negatif ve anlamlı ilişkili tespit edilmiştir.

\subsubsection{TFV-Hissedar Getirisi Illişkisi-Mann Whitney U Testi}

Verimlilik değişimi ile hissedar getirisi arasındaki ilişkiyi test etmek amacıyla yapılan ikinci analiz, Mann-Whitney $U$ testidir. Bunun için, TFV ve TED açısından verimlilik değişimleri negatif olan bankalar diğerlerinden ayrılmış ve iki ayrı kümeleme için verimlilik değişimi azalan ve azalmayan bankaların hissedar getirileri arasında anlamlı bir fark olup olmadığına bakılmıştır. Bulgular Tablo 12' de yer almaktadır.

Tablo 12. Verimlilik Kümeleri ve Hissedar Getirisi: Mann-Whitney U Testi Sonuçları

\begin{tabular}{|c|c|c|c|c|}
\hline Değişkenler & Kümeler & Sıra Ortalaması & $Z$ & Anlamlılık \\
\hline \multirow{2}{*}{$\begin{array}{l}\text { Toplam Faktör } \\
\text { Verimlilik Endeksi }\end{array}$} & $\begin{array}{l}\text { 1: sabit ya da pozitif } \\
\text { değişim }\end{array}$ & 52,07 & \multirow[t]{2}{*}{$-0,479$} & \multirow{2}{*}{0,632} \\
\hline & $0:$ negatif değişim & 49,27 & & \\
\hline \multirow{2}{*}{$\begin{array}{l}\text { Teknik Etkinlik } \\
\text { Değişimi }\end{array}$} & $\begin{array}{l}\text { 1: sabit ya da pozitif } \\
\text { değişim }\end{array}$ & 53,97 & \multirow[t]{2}{*}{$-2,191$} & \multirow[t]{2}{*}{0,028} \\
\hline & $0:$ negatif değişim & 38,87 & & \\
\hline
\end{tabular}

Tablo 12'deki değerler, regresyon analizini desteklemektedir. Buna göre TFV azalan bankalarla artan ve değişmeyen bankaların hissedar getirileri arasında anlamlı bir fark yoktur. Ancak TED açısından bu farkın anlamlı olduğu görülmektedir.

\subsubsection{TFV-Hissedar Getirisi illişkisinin Kontrol Değişkenleri ile Test Edilmesi}

Çalışmada hissedar getirisi ve verimlilik değişimi arasındaki ilişki istatistiksel olarak belirlendikten sonra, bu ilişkinin tutarlıığını ortaya koymak için, literatürde hisse senedi getirileri ile genel olarak ilişkili bulunan kontrol değişkenleri kullanılarak sağlamlık testleri yapılmıştır. Buna göre, Piyasa getirisi, Defter Değeri/Piyasa Değeri Rasyosu (DD/PD) ve Aktif Karlılığı Rasyosu (ROA) olmak üzere üç değişken modellere dahil edilmiştir. Literatürde hisse senedi getirilerinin açıklanmasında gerek Sermaye Varlıklarını Fiyatlama Modelinin gerekse indeks modellerin önerdiği şekilde piyasa getirisinin risksiz faiz oranını aşan kısmı değişken olarak kullanılmaktadır. Ancak bu çalışmada bağımlı değişken Hissedar Getirisi olduğundan ve hesaplanmasında risksiz faiz oranı dikkate alınmadığından, bağımsız değişken olarak doğrudan doğruya BiST 100 endeksinin getirisi kullanılmıştır. Bu üç değişkenden ayrı olarak ölçeği temsilen iki değişken (toplam aktiflerin logaritması ve hisse senetlerinin toplam piyasa değeri) analizlere dahil edilmiş fakat katsayıları anlamlı bulunmadığı için modelden çıkartılmıştır. Kontrol değişkenlerinden DD/PD ve ROA' ya ait referanslar ise Tablo $13^{\prime}$ te yer almaktadır.

Tablo 13. Kontrol Değişkenlerine Illişkin Referanslar

\begin{tabular}{|l|l|l|}
\hline Değişken Adı & \multicolumn{1}{|c|}{ Açıklaması } & \multicolumn{1}{|c|}{ Referans } \\
\hline DD/PD & \multicolumn{1}{|c|}{$\begin{array}{l}\text { Fama ve French (1992); Fama ve French (1995); Yıldırım } \\
\text { (1997); Pontiff ve Schall (1998); Lewellen (1999); } \\
\text { Kisse senetlerinin Defter } \\
\text { Değeri/Piyasa Değeri oranı } \\
\text { (2012); Hahn ve Yoon (2016) }\end{array}$} \\
\hline Aktif Karlılığı & Net Kar/Toplam Aktifler oranı & $\begin{array}{l}\text { Aydemir, Ögel ve Demirtaş (2012); Ayaydın ve Karaaslan } \\
\text { (2014); Menike vd. (2015); Demirci ve Şahin (2015); } \\
\text { Anwaar (2016); Acaravcı (2016) }\end{array}$ \\
\hline
\end{tabular}


Kullanılan kontrol değişkenlerine ilişkin tanımlayıcı istatistikler Tablo 14'de gösterildiği şekildedir. Piyasa getirisi en düşük -0,5136 düzeyinde gerçekleşmiş, en yüksek olarak ise 0,9664 düzeyine çıkmıştır. DD/PD'nin ortalamasının 1'e oldukça yakın olduğu gözlemlenmiş, Defter değeri, piyasa değerinin maksimum 2,22 katı olarak gerçekleşmiştir. ROA ise, minimum $-0,0026$ düzeyinde gerçekleşmişken, maksimum 0,0343 seviyesine çıkmıştır.

Tablo 14. Kontrol Değişkenleri Tanımlayııı İstatistikleri

\begin{tabular}{|l|c|c|c|}
\hline & Piyasa Getirisi & DD/PD & Aktif Karlılığı \\
\hline Ortalama & 0,1477 & 0,9377 & 0,0159 \\
Medyan & 0,1694 & 0,8811 & 0,0154 \\
Maksimum & 0,9664 & 2,2222 & 0,0343 \\
Minimum & $-0,5136$ & 0,2874 & $-0,0026$ \\
Standart Sapma & 0,4105 & 0,4487 & 0,0068 \\
Gözlem Sayısı & 100 & 100 & 100 \\
\hline
\end{tabular}

Tutarlılı̆ı ortaya koymak için kullanılan değişkenlerin durağanlık sınamaları yapılmış olup, sonuçlar Tablo 15'de yer almaktadır. Buna göre düzeyde durağan olmayan DD/PD oranı ve Aktif Karlılığı değişkenleri, birinci farkları alınarak durağan hale getirilmişlerdir. Durağanlık testlerine ilişkin sonuçlar Tablo $15^{\prime}$ de sunulmuştur.

Tablo 15. Durağanlık Testleri İstatistik Değerleri

\begin{tabular}{|l|l|l|l|l|l|l|}
\hline \multirow{2}{*}{ Değişkenler } & \multicolumn{3}{|c|}{ Sabitli } & \multicolumn{3}{|c|}{ Sabitli ve Trendli } \\
\cline { 2 - 7 } & Levin, Lin \& & Im, Pesaran & ADF - Fisher & Levin, Lin \& & Im, Pesaran & ADF - Fisher \\
& Chu t & Shin W-stat & Chi-square & Chu t & Shin W-stat & Chi-square \\
TFV $\{0\}$ & $-4,37965^{*}$ & $-2,77103^{*}$ & $44,1532^{*}$ & $-9,32025^{*}$ & $-1,73834^{*}$ & $48,7406^{*}$ \\
TET $\{0\}$ & $-95,4185^{*}$ & $-22,0644^{*}$ & $34,6876^{*}$ & $-54,288^{*}$ & $-6,39235^{*}$ & $27,5875^{*}$ \\
TEK $\{0\}$ & $-9,43987^{*}$ & $-4,21588^{*}$ & $60,0255^{*}$ & $-12,4758^{*}$ & $-2,20667^{*}$ & $56,4067^{*}$ \\
Piyasa Getirisi $\{0\}$ & $-8,72351^{*}$ & $-4,47047^{*}$ & $62,5048^{*}$ & $-28,0143^{*}$ & $-7,00446^{*}$ & $125,389^{*}$ \\
DD/PD $\{1\}$ & $-2,21021^{*}$ & $-2,85031^{*}$ & $47,0596^{*}$ & $-1,25233^{*}$ & $-0,53326^{*}$ & $30,3874^{*}$ \\
Aktif Karlılı̆ı $\{1\}$ & $-3,9806^{*}$ & $-2,3166^{*}$ & $39,9422^{*}$ & $-6,1137^{*}$ & $-0,5160^{*}$ & $29,2516^{*}$ \\
\hline
\end{tabular}

Not: * sembolü \%1 anlamlılık düzeyinde istatistiksel olarak anlamlı olan katsayıları ifade etmektedir.

Kontrol değişkenleri eklendikten sonra hissedar getirisi ve verimlilik değişimi arasındaki ilişkinin sonuçları Tablo $16^{\prime}$ da verilmiştir. Analizler Hausman testi sonuçları dikkate alınarak rassal etkiler modeli ile gerçekleştirilmiştir.

Tablo 16. Hissedar Getirisi Verimlilik Değişimi Iliş̧kisi (Sağlamlık Testleri)

\begin{tabular}{|c|c|c|c|c|c|c|c|c|}
\hline \multirow{2}{*}{\begin{tabular}{|l} 
Bağımlı \\
Değişken: \\
Hissedar \\
Getirisi
\end{tabular}} & \multicolumn{3}{|c|}{ Bağımsız Değişkenler } & \multicolumn{3}{|c|}{ Kontrol Değişkenleri } & \multirow[b]{2}{*}{$R 2$} & \multirow[b]{2}{*}{$\begin{array}{l}\text { Durbin } \\
\text { Watson }\end{array}$} \\
\hline & TFV & TED & TD & $\begin{array}{l}\text { Piyasa } \\
\text { Getirisi }\end{array}$ & $\mathrm{DD} / \mathrm{PD}$ & $\begin{array}{l}\text { Aktif } \\
\text { Karlılığı }\end{array}$ & & \\
\hline Model I & $\begin{array}{l}-0,1315 \\
(-0,5019)\end{array}$ & & & \begin{tabular}{|l|}
$0,7079 * * *$ \\
$(7,6884)$
\end{tabular} & $\begin{array}{l}-0,6632 * * * \\
(-8,0208) \\
\end{array}$ & $\begin{array}{l}-19,0271^{* * *} \\
(-3,0685)\end{array}$ & 0,7972 & 2,0165 \\
\hline Model II & & $\begin{array}{l}0,8841 \\
(1,4048)\end{array}$ & & $\begin{array}{l}0,7040 * * * \\
(7,8283)\end{array}$ & $\begin{array}{l}-0,6343 * * * \\
(-7,5753)\end{array}$ & $\begin{array}{l}-17,7169^{* * *} \\
(-3,0116)\end{array}$ & 0,8014 & 2,0686 \\
\hline Model III & & & $\begin{array}{l}-0,2402 \\
(-0,9205)\end{array}$ & $\begin{array}{l}0,6980 * * * \\
(7,5468)\end{array}$ & $\begin{array}{l}-0,6577^{* * *} \\
(7,9787)\end{array}$ & $\begin{array}{l}-19,5930 * * * \\
(-3,1927)\end{array}$ & 0,7987 & 2,0338 \\
\hline
\end{tabular}

Not: ${ }^{* * *}$ sembolü \%1 anlamlılık düzeyinde istatistiksel olarak anlamlı olan katsayıları ifade etmektedir. 
Tablo $16^{\prime}$ da analize giren değişkenlerin katsayıları ve parantez içerisinde $t$ istatistiği değerleri yer almaktadır. Kontrol değişkenleri eklenerek tekrarlanan analizler sonucunda hissedar getirisi üzerinde etkinlik değişimlerinin etkili olduğuna dair bir bulgu elde edilememiştir.

\section{Sonuç ve Tartışma}

Bu çalışmanın odağında Türkiye'deki mevduat bankalarının verimlilik değişimlerinin incelenmesi yer almaktadır. Bu amaçla, bankaların nispi verimlilik değerlerinin zamana göre değişimini ölçen Malmquist TFV endeksi kullanılmıştır. Analizler sonucunda 16 yıllık dönemde Türk Bankacılık Sektörünün ortalama verimliliğinin çoğu yıllarda düştüğü, bunun da teknolojik değişimde yaşanan düşüşten kaynaklandığı anlaşılmışır.

Burada unutulmaması gereken nokta, toplam faktör verimliliği değerlerinin düştüğü bir dönemde sektörün verimsiz-etkin olmadığı şekilde yorumlanamayacağıdır. Elde edilen sonuçlar, yalnızca bir önceki döneme göre verimlilik değerlerinin hangi yönde nasıl değiştiğini göstermektedir. Bu düşüşler iki verimli dönem arasında da yaşanabilir.

Çalışmada elde edilen en önemli bulgu, verimlilik değişimi ile hissedar getirisi arasındaki anlamlı ilişkidir. Bu ilişki TED açısından pozitif, TD açısından ise negatif yönlüdür.

Çalışmanın çıktı odaklı olarak yapıldığı da göz önünde bulundurularak, çıktılarını arttırarak üretim sınırını yakalamaya çalışan bankaların aynı dönemde hissedar getirilerinin de arttığı, üretim sınırından uzaklaşan bankaların ise hissedar getirilerinin de azaldığı anlaşılmaktadır.

Yenilik göstergesi olarak da yorumlanabilen TD ise, teknolojik gerileme dönemlerinde, girdi-çıktı değişkenlerinin olumsuz değişiminin aksine hissedar getirilerinin arttığını, teknolojik gelişimin dönemlerinde ise olumlu girdi-çıktı değişimlerine rağmen hissedar getirilerinin azalmış olduğunu göstermektedir. Teknolojik değişim yorumlanırken, ele alınan karar verme birimlerinin maruz kaldığı dışsal etkiler ve bu etkiler sonucu optimal girdi - çıktı bileşen seviyelerini aşağı veya yukarı yönlü hareket ettirmek durumunda kaldıkları gerçeği göz ardı edilmemelidir. Bu durumda özellikle finansal, ekonomik ve siyasi dalgalanmaların yaşandığı dönemlerde, bankaların teknolojik değişimlerinin negatif yönlü olduğu gözlemlenmektedir. Aynı dönemlerde sektör bazında etkinlik sınırı aşağı yönlü bir hareket sergilemiş olsa da, bu koşullar altında dahi etkin olabilmek adına bir hareket olduğu teknik etkinlik değişimi sonuçları izlenerek tespit edilebilir.

TED ve TD ile hissedar getirileri arasında bulunan bu anlamlı ilişkinin sağlamlığını kontrol edebilmek için piyasa getirisi, DD/PD ve ROA kontrol değişkenleri kullanılarak analizler tekrar yapılmıştır. Kontrol değişkenleri kullanılarak yapılan sağlamlık testleri, hissedar getirisi üzerinde TFV, TED ve TD değişkenlerinden hiçbirinin anlamlı bir etkisi olmadığını ortaya koymuştur.

Hissedar getirileri ile verimlilik değişimleri arasında yapılan çalışma sonuçları değerlendirilirken hissedarların verimlilik değişimleri yahut dönemsel verimlilik skorlarından herhangi birini dikkate alabileceği de unutulmamalıdır. Yukarıda bahsedildiği üzere, birbirini takip eden iki etkin dönem arasında bir verimlilik azalışı yaşanmış olabilir. Ancak bu durumda yatırımcılar verimlilik azalışını değil, tek dönem bazında ele alınan birimin etkin oluşunu dikkate alarak bu birimin paylarına yönelebilirler. Böylelikle, paylar üzerindeki artan talep, fiyatları yukarı yönlü hareket ettirecek ve hissedar getirilerinde bir artış yaşanacaktır.

Ayrıca piyasaların her türlü habere oldukça duyarlı olması, yatırımcıların çok kısa vadeli yatırımları tercih etmesi ve piyasa da önemli olabilecek bilgilere erişimde sıkıntılar yaşanıyor olması gibi etkenler de elde edilen sonuçları etkileyecektir.

İleride yapılması planlanan çalışmalarda, daha uzun dönemli bir analize imkan sağlaması açısından, hissedar getirileri ve verimlilik değerleri çeyrek dönemler bazında hesaplanabilir. Ayrıca VZA metodunun bir sonucu olarak ele alınacak farklı girdi - çıktı bileşenleri ile hesaplanan Malmquist sonuçlarına göre hissedar getirileri ve verimlilik değişimleri arasında farklı ilişkiler de ortaya konulabilir. Ancak burada gözden kaçırılmaması gereken nokta, seçilen girdi - çıktı değişkenlerinin ele alınan karar verme birimlerini en iyi şekilde yansıtması gerekliliğidir. 


\section{Son Notlar}

* 04-05 Mayıs 2018 tarihleri arasında Başkent Üniversitesi tarafından düzenlenen 1. Uluslararası Bankacılık Kongresinde sunulan ve bildiriler kitabında yayınlanan "Etkinlik Ve Verimlilik Değişimleri Ile Hissedar Getirileri Arasındaki Iliş̧ki: Türk Bankacılık Sektörü Üzerine Bir Uygulama” başlıklı çalışmanın genişletilmiş ve düzenlenmiş halidir.

\section{Kaynaklar}

Abdul, M., Muhammed, Z., \& Sufian, F. (2008). Bank eficiency and share prices in China: Empirical evidence from a threestage banking model. Munich Personel RePEc Archive, Germany.

Acaravcı, S. K. (2016). Finansal oranlar ve hisse senedi getirisi ilişkisi: Borsa İstanbul üzerine bir uygulama. Mustafa Kemal Üniversitesi Sosyal Bilimler Enstitüsü Dergisi, 13(35), 263-275.

Aftab, M., Ahamad, S., Ullah, W., \& Sheikh, R. A. (2011). The impact of bank efficiency on share performance: Evidence from Pakistan. African Journal of Business Management, 5(10), 3975-3980.

Anwaar, M. (2016). Impact of firms performance on stock returns (evidence from listed companies of FTSE-100 Index London-UK). Global Journal of Management and Business Research, 16.

Ayaydın, H., \& Karaaslan, í. (2014). Ülke riskinin hisse senedi fiyatlarına etkisi: Türk bankacılık sektöründe bir araştırma. Gümüşhane Üniversitesi Sosyal Bilimler Enstitüsü Elektronik Dergisi, 5(10), 1-27.

Aydemir, O., Ögel, S., \& Demirtaş, G. (2012). Hisse senetleri fiyatlarının belirlenmesinde finansal oranların rolü. Celal Bayar Üniversitesi IiBF Yönetim ve Ekonomi Dergisi, 19(2), 277-288.

Berg, S. A., Forsund, F. R., \& Jansen, E. S. (1992). Malmquist indices of productivity growth during the deregulation of Norwegian banking, 1980-89. The Scandinavian Journal of Economics, 94, 211-228.

Canhoto, A., \& Dermine, J. (2003). A note on banking efficiency in Portugal, new vs. old banks. Journal of Banking \& Finance, 27(11), 2087-2098.

Caves, D. W., Christensen, L. R., \& Diewert, W. E. (1982). The economic theory of index numbers and the measurement of input, output and productivity. Econometrica, Journal of the Econometric Society, 50(6), 1393-1414

Chu, S. F., \& Lim, G. H. (1998). Share performance and profit efficiency of banks in an oligopolistic market: Evidence from Singapore. Journal of Multinational Financial Management, 8(2-3), 155-168.

Cingi, S., \& Tarım, A. (2000). Türk banka sisteminde performans ölçümü DEA-Malmquist TFP endeksi uygulaması. TBB Araştırma Tebliğleri Serisi, 01, 1-34.

Demirci, E., \& Şahin, S. (2015). Uluslararası ortaklık yapısının hisse senedi getirisi üzerindeki etkisi: Borsa İstanbul uygulaması. Ekonomik ve Sosyal Araştırmalar Dergisi, 11(1), 93-105.

Devaney, M., \& Weber, W. L. (2000). Productivity growth, market structure and technological change: Evidence from the rural banking sector. Applied Financial Economics, 10(6), 587-595.

Drake, L., Hall, M. JB, \& Simper, R. (2009) Bank modelling methodologies: A comparative non-parametric analyisis of efficiency in the Japanese banking sector. Journal of International Financial Markets, Institutions and Money, 19(1), 1-15.

Fama, E. F., \& French, K. R.(1992). The cross-section of expected stock returns. The Journal of Finance, 47(2), 427-465.

Fama, E. F., \& French, K. R. (1995). Size and book-to-market factors in earnings and returns. The Journal of Finance, 50(1), 131-155.

Fiordelisi, F., \& Molyneux, P. (2010). Total factor productivity and shareholder returns in banking. OMEGA, 38(5), 241253.

Guzman, I., \& Reverte, C. (2008). Productivity and efficiency change and shareholder value: Evidence from the Spanish banking sector. Applied Economics, 40(15), 2037-2044.

Güzeldere, H., \& Sarıoğlu, S. E. (2012). Varlık fiyatlamada Fama-French Üç Faktörlü Model'in geçerliliği: IMKB üzerine bir araştırma. Business and Economics Research Journal, 3(2), 1-19.

Hahn, J., \& Yoon, H. (2016). Determinants of the cross-sectional stock returns in Korea: Evaluating recent empirical evidence. Pasific-Basin Financial Journal, 38, 88-106.

Karacabey, A., \& Arslan, B. (2004) Analyzing the production changes of the Turkish banking system. https://dx.doi.org/10.2139/ssrn.485582 
Kasman, S., \& Kasman, A. (2011). Efficiency, productivity and stock performance: Evidence from the Turkish banking sector. Panoeconomicus, 58(3), 355-372.

Kheradyar, S., Ibrahim, I., \& Nor, M. F. (2011). Stock return predictability with financial ratios. International Journal of Trade, Economics and Finance, 2(5), 391-396.

Krishnasamy, G., Hanuum Ridzwa, A., \& Perumal, V. (2004) Malaysian post merger banks' productivity: Application of Malmquist productivity index. Managerial Finance, 30(4), 63-74.

Kurşun, S., \& Kuşakçı, A. O. (2016) Bankacılık sektöründe veri zarflama analizi ile etkinliğin değerlendirilmesi literatür taraması. İstanbul Ticaret Üniversitesi Fen Bilimleri Dergisi, 15(30), 133-151.

Lee, B. L., Worthington, A. C., \& Leong, W. H. (2010). Malmquist indices of pre-and post-deregulation productivity, efficiency and technological change in The Singaporean banking sector. The Singapore Economic Review, 55(04), 599-618.

Lewellen, J. (1999). The time-series relations among expected return, risk and book-to-market. Journal of Financial Economics, 54(1), 5-43.

Liadaki, A., \& Gaganis, C. (2010). Efficiency and stock performance of EU banks: Is there a relationship? OMEGA, 38(5), 254-259.

Lorcu, F. (2010). Malmquist toplam faktör verimlilik endeksi: Türk otomotiv sanayi uygulaması. İstanbul Üniversitesi Işletme Fakültesi Dergisi, 39(2) 276-289.

Mazgit, İ., \& Balaylar, N. A. (2013). Türkiye'de yabancı sermayeli bankaların etkinlik analizi. Yönetim ve Ekonomi Araştırmaları Dergisi, 11(21) 317-348.

Menike, L.M.C.S., Dunusinghe, P.M. \& Ranasinghe A. (2015). Macroeconomic and firm specific determinants of stock returns: A comparative analysis of stock markets in Sri Lanka and in the United Kingdom. Journal of Finance and Accounting, 3(4), 86-96.

Pontiff, J., \& Schall, L. D. (1998). Book-to-market ratios as predictors of market returns. Journal of Financial Economics, 49(2), 141-160.

Sathye, M. (2002). Measuring productivity changes in Australian banking: An application of Malmquist indices. Managerial Finance, 28(9), 48-59.

Türkiye Bankalar Birliği, www.tbb.org.tr, 01/04/2018

Wen, J., Wang, X., \& Sun, T. (2011). X-efficiency and shareholder returns: Evidence from listed commercial banks. On Economic Problems, 9, 23.

Yalçıner, K., Atan, M., \& Boztosun, D. (2005). Finansal oranlarla hisse senedi getirileri arasındaki ilişki. Muhasebe ve Finansman Dergisi, 27, 176-187.

Yamaltdinova, A., Yıldız, F., \& Eleren A. (2016). Girişimcilik örneği olarak bankacılık sektöründe Malmquist yöntemiyle kârlılık temelinde etkinlik analizi: Kırgızistan örneği. MANAS Sosyal Araştırmalar Dergisi, (5)5, 105.

Yıldırım, N. (1997). Firma büyüklüğü ve defter değeri-piyasa değeri etkileri: IMKB örneği. iMKB Dergisi, 8(31), 2-17. 